BMJ Open Diabetes Research \& Care

\title{
Relationship of obesity to adipose tissue insulin resistance
}

\author{
Jiajia Jiang, ${ }^{1,2}$ Xueli Cai, ${ }^{3}$ Yuesong Pan $(1),{ }^{4,5}$ Xiaoyan Du, ${ }^{6}$ Huiping Zhu, ${ }^{1}$ \\ Xinghua Yang, ${ }^{1}$ Deqiang Zheng, ${ }^{1}$ Herbert Gaisano, ${ }^{7}$ Tiemin Wei, ${ }^{3}$ Yan He (i] ${ }^{1,8}$
}

To cite: Jiang J, Cai $X$, Pan Y, et al. Relationship of obesity to adipose tissue insulin resistance. BMJ Open Diab Res Care 2020;8:e000741. doi:10.1136/ bmjdrc-2019-000741

- Additional material is published online only. To view please visit the journal online (http://dx.doi.org/10.1136/ bmjdrc-2019-000741).

JJ and XC contributed equally.

Received 11 July 2019

Revised 5 January 2020

Accepted 19 January 2020

\section{Check for updates}

(C) Author(s) (or their employer(s)) 2020. Re-use permitted under CC BY-NC. No commercial re-use. See rights and permissions. Published by BMJ.

For numbered affiliations see end of article.

Correspondence to

Dr Yan He;

yanhe1220@126.com and Dr

Yuesong Pan;

yuesongpan@ncrend.org.cn

\section{ABSTRACT}

Aims This study aimed to examine the association of different anatomical forms of obesity with adipose tissue insulin resistance and to assess the diagnostic value and contribution of obesity to adipose tissue insulin resistance. Methods This cross-sectional study included a total of 499 subjects aged 50 years or over. Multivariate regression analysis was conducted to clarify the association of different forms of obesity with adipose tissue insulin resistance (calculated as fasting insulin level xfasting free fatty acids level). Receiver operating characteristic cure analyses were used to assess the diagnostic value of each anthropometric indicator for adipose tissue insulin resistance. Attributable risk per cent and population attributable risk per cent were calculated to assess the contribution of obesity to adipose tissue insulin resistance. Results After adjustment for potential confounders, we showed that anthropometric indicators were all positively associated with adipose tissue insulin resistance. In males, waist circumference (WC) was the strongest associated factor (OR, $3.43(95 \% \mathrm{Cl} 2.03$ to 5.82$)$ ) and indicator (area under the curve (AUC): 0.79 ) of adipose tissue insulin resistance among those indicators. Here, abdominal obesity $(\mathrm{WC} \geq 90 \mathrm{~cm}$ ) accounted for $64.9 \%$ of adipose tissue insulin resistance in the abdominal obese males. Accordingly, body mass index (BMI) was the strongest associated factor (0R,3.08 (95\% Cl 2.04 to 4.66)) and indicator (AUC: 0.78 ) of adipose tissue insulin resistance in females. Here, general obesity of $B M l \geq 25 \mathrm{~kg} / \mathrm{m}^{2}$ accounted for $66.2 \%$ of the adipose tissue insulin resistance in the general obese females. We further demonstrated that adipose tissue insulin resistance was associated or trended to be associated with the metabolic diseases of cardiovascular disease, type 2 diabetes and fatty liver in subjects with normal BMl and WC.

Conclusions Maintaining WC in males and BMI in females to a normal range could be an important strategy to significantly reduce the occurrence of adipose tissue insulin resistance and the subsequent metabolic diseases.

\section{INTRODUCTION}

Adipose tissue is a highly insulin-responsive organ that largely contributes to both glucose and lipid metabolism. ${ }^{1}$ Impairment of insulin action on the adipose tissue, herein termed as adipose tissue insulin resistance, is an important contributor to systemic insulin resistance $^{2}$ and is a major risk factor for metabolic diseases, including diabetes, ${ }^{3}{ }^{4}$ nonalcoholic steatohepatitis ${ }^{56}$ and cardiovascular

\section{Significance of this study}

What is already known about this subject?

- Animal and mechanistic studies have shown that hypertrophy and hyperplasia of adipocytes can induce inflammation as a major cause of adipose tissue insulin resistance.

- Current population-based studies have only demonstrated that adipose tissue insulin resistance is higher in subjects with general obesity.

What are the new findings?

- General obesity and obesity in the upper body and abdomen are all associated with increased risk of adipose tissue insulin resistance.

- Abdominal and general obesity are superior clinical markers in predicting adipose tissue insulin resistance in males and females, respectively.

How might these results change the focus of research or clinical practice?

- Adipose tissue insulin resistance was associated or trended to be associated with metabolic disease even in subjects who did not exhibit general and abdominal obesity. This result indicates that metabolic disease can also develop in lean subjects, which may be attributed to a decrease in insulin sensitivity in the adipose tissue.

- Prevalence of metabolic disease in subjects with adipose tissue insulin resistance is relatively higher than their partners with same obesity phenotype, which indicates that targeting adipose tissue insulin resistance per se rather than obesity may be a novel strategy to prevent metabolic diseases, even in the lean subjects.

disease (CVD). ${ }^{7}$ The current gold standard of measuring adipose tissue insulin sensitivity is the multistep pancreatic clamp technique that accurately determines lipolysis fluxes by employing tracer dilution techniques during continuous intravenous insulin infusion. However, the utilization of this method has been restricted by its technical complexity and expensive cost. In recent years, a simplified measurement method has been well established by calculating the adipose tissue insulin resistance index (Adipo-IRI) from the plasma concentrations of fasting insulin and 
fasting free fatty acids (FFA), which was found to be well correlated with a 50\% suppression of lipolysis (IC50) as measured by the multistep pancreatic clamp technique $(\mathrm{r}=0.86) .{ }^{910}$ To demonstrate feasibility of this method, the Adipo-IRI has been used in several population studies. ${ }^{467}$

Some basic molecular studies supported by animal studies have well documented that hypertrophy and hyperplasia of adipocytes can induce inflammation as a major underlying cause of insulin resistance of adipose tissue. ${ }^{11-14}$ To our knowledge, there were only limited population-based studies that have assessed the relationship between obesity and adipose tissue insulin resistance. Several recent studies have examined the differences of Adipo-IRI across the spectrum from normal weight to obesity as defined by body mass index (BMI), which demonstrated that the Adipo-IRI in young ${ }^{1516}$ and adult ${ }^{4}$ obese subjects was about twofold higher than normal weight subjects. Obesity is a highly heterogeneous condition whereby fat is distributed in different regions of the body, which can be assessed by various anthropometric measurements or indicators. These anthropometric indicators include BMI, neck circumference (NC), waist circumference (WC) and waist/hip ratio (WHR), which have been used to measure total, upper or abdominal obesity, respectively. Several studies have indicated that abdominal (WC/WHR) and upper body (NC) obesity were either similar or stronger indicators of metabolic diseases than general obesity (ie, BMI) ${ }^{17-19}$ When the utilization of WC was not applicable in some clinical situations, such as pregnancy, ascites and abdominal tumors, the NC could be used as a more convenient clinical alternative. Therefore, more detailed information about the relationship of obesity to adipose tissue insulin resistance is needed, such as what anatomical forms of obesity are most closely related to adipose tissue insulin resistance? The predictive value and contribution of obesity to adipose tissue insulin resistance in the general population are also unclear. Elucidation of such important questions could be useful in understanding how obesity influences adipose tissue insulin resistance on a population level, which could therefore provide a direct basis for choosing the adipose tissue to target when treating metabolic disorder.

In this study, we have systemically examined the association of the distinct forms of anatomical obesity as defined by various anthropometric indicators with adipose tissue insulin resistance; and we also determined which anthropometric indicators have better predictive value for adipose tissue insulin resistance. Furthermore, we also assessed the contribution of obesity to adipose tissue insulin resistance.

\section{SUBJECTS AND METHODS}

\section{Subjects}

This cross-sectional study was conducted from April to October of 2017 in the community of Lishui, a city in the Zhejiang Province, China. All the residents in the community at age of 50 or over $(n=546)$ were invited to participate in the study. The trained local community workers contacted each invited subject by using a door-to-door method. Five hundred and twelve residents agreed to participate in the study and were scheduled for a personal interview and a clinic visit. After excluding subjects for any pathology or medical intervention that could alter the anthropometric indicators, including neck malformation, prior neck surgery, thyromegaly, cancer and incomplete information of anthropometric parameters or laboratory examination, 499 subjects were finally included in this analysis. All subjects gave written informed consent before entering the study in accordance with the Declaration of Helsinki. The protocol was approved by the Committee of Lishui Central Hospital.

\section{Data collection}

A standard questionnaire completed by an in-person interview was used to collect the information, including demographics (age, sex, income and education level), behavior (smoking and alcohol drinking status) and the history of current diseases and corresponding medications used.

A standardized protocol was performed to obtain the anthropometric information, including weight, height, NC, WC, hip circumference (HC) and blood pressure. Weight and height were assessed to the nearest $0.1 \mathrm{~kg}$ and $0.1 \mathrm{~cm}$ by an electronic weight scale and vertical height meter with the study subjects wearing only light clothing and no shoes. A measuring tape was used to measure the following body circumferences. NC was measured along the inferior margin of the laryngeal prominence and perpendicular to the long axis of the neck, with the subject remaining standing and the head in the horizontal plane position. WC was measured at the horizontal plane between the inferior costal margin and the iliac crest along the mid-axillary line. $\mathrm{HC}$ was measured at the widest point between the waist and the thigh. All circumferences were recorded to within $0.1 \mathrm{~cm}$. Blood pressure was measured three times using a mercury sphygmomanometer after at least a 5 min rest in the sitting position, and the mean value of the three readings was recorded.

All laboratory examinations were performed in the Central Hospital of Lishui. Blood samples were obtained after an overnight fast to assess the fasting plasma glucose (FPG), fasting insulin, lipid profiles and FFA. Participants without a validated history of diabetes underwent a $75 \mathrm{~g}$ oral glucose tolerance test, whereas participants with a history of diabetes underwent a $100 \mathrm{~g}$ carbohydrate diet test; and in the latter, blood samples were collected 2 hours after glucose loading (2-hour plasma glucose $(\mathrm{PG})$ ) to assess glucose tolerance. PG was measured by the hexokinase/glucose oxidation method. FFA levels were measured with an enzymatic method. Insulin levels were measured by radioimmunoassay. Total cholesterol (TC), triglycerides (TG) and high-density lipoprotein cholesterol (HDL-C) were measured by the oxidase method, and low-density lipoprotein cholesterol (LDL-C) was 
derived from the lipids measured using the Friedewald calculation. $^{20}$

\section{Definitions}

Alcohol drinking and smoking status were classified as: never drank/smoked, drinking/smoking and quit drinking/smoking. Education level was classified as low (illiteracy or primary education), intermediate (junior to senior secondary education or vocational education) and high (higher vocational or university education).

Diabetes mellitus was diagnosed as FPG $\geq 7.0 \mathrm{mmol} / \mathrm{L}$ and/or 2-hour $\mathrm{PG} \geq 11.1 \mathrm{mmol} / \mathrm{L}$, or when on drug treatment for diabetes mellitus. Hypertension was defined as systolic blood pressure (SBP) $\geq 140 \mathrm{~mm} \mathrm{Hg}$ and/or diastolic blood pressure (DBP) $\geq 90 \mathrm{~mm} \mathrm{Hg}$ or when the subject is on antihypertensive medications. The definition of dyslipidemia includes $\mathrm{TG} \geq 1.7 \mathrm{mmol} / \mathrm{L}$ or $\mathrm{TC} \geq 5.2 \mathrm{mmol} / \mathrm{L}$ or HDL-C $\leq 1.0 \mathrm{mmol} / \mathrm{L}$ (as per Joint Committee for Developing Chinese guidelines on Prevention Treatment of Dyslipidemia in Adults) or when the subject is on drug treatment for hyperlipidemia. Prevalent CVD was defined as a history of coronary heart disease, heart failure and stroke.

BMI was calculated as the ratio of weight $(\mathrm{kg})$ to the square of the height $(\mathrm{m})$. General obesity was defined as $\mathrm{BMI} \geq 25 \mathrm{~kg} / \mathrm{m}^{2} \quad$ (WHO/IASO/IOTF, 2000) and abdominal obesity as $\mathrm{WC} \geq 90 \mathrm{~cm}$ for male or $\mathrm{WC} \geq 80 \mathrm{~cm}$ for female. Adipo-IRI was calculated as fasting insulin level $\times$ fasting plasma FFA level. ${ }^{9}{ }^{10}$ Adipose tissue insulin resistance was defined as the highest tertile $\left(\mathrm{P}_{66.7}\right)$ of the Adipo-IRI. ${ }^{21}$

\section{Statistical analysis}

All analyses and graphs were performed using the SPSS software V.23 for Windows (SPSS, Chicago, Illinois, USA, RRID: SCR_002865) and R V.3.3.1 (R development core team; available from http://www.r-project.org/, RRID: SCR_001905). The data were expressed as means \pm SD for normal continuous variables, median (IQR) for nonnormal continuous variables or numbers (percentages) for categorical variables. To examine differences in characteristics between groups with adipose tissue insulin resistance versus groups with non-adipose tissue insulin resistance, we performed two-sample t-test for normal continuous variables, Mann-Whitney $\mathrm{U}$ test for nonnormal continuous variables and $\chi^{2}$ test for categorical variables. Correlations between anthropometric indicators and Adipo-IRI were assessed by linear regression analysis. The association of anthropometric indicators with adipose tissue insulin resistance was assessed by logistic regression analysis, in which the potential confounding factors were adjusted as indicated. Z-score transformation was performed for anthropometric indicators before the regression analysis to fulfill the comparability of variables. Receiver operating characteristic (ROC) cure analysis was used to identify the cut-off point of anthropometric indicators for adipose tissue insulin resistance. To assess the contribution of obesity to adipose tissue insulin resistance among the obese subjects versus the whole study subjects, attributable risk per cent (ARP) (1) and population attributable risks per cent (PARP) (2) were estimated. ARP and PARP can be calculated as follows:

$$
\begin{aligned}
& A R P=(I e-I o) / I e \times 100 \%, \\
& P A R P=(I t-I o) / I t \times 100 \%,
\end{aligned}
$$

It denotes the prevalence of adipose tissue insulin resistance in all subjects of the study; $I e$ is the prevalence of adipose tissue insulin resistance in obese subjects and $I o$ is the prevalence of adipose tissue insulin resistance in non-obese subjects. All analyses were performed separately for gender. $\mathrm{P}<0.05$ were considered to be statistically significant.

\section{RESULTS}

\section{Characteristics of the participants}

In this cross-sectional study, $232(46.5 \%)$ males and 267 $(53.5 \%)$ females with a mean age of $60.1 \pm 6.8$ years were included. Among them, 85 (17.0\%) subjects had diabetes, $40(8.0 \%)$ subjects had CVD and $51(10.2 \%)$ subjects had fatty liver. The medium Adipo-IRIs were 1.87 (IQR 1.22-3.10) and 2.84 (IQR 2.00-4.19) for male and female subjects, respectively. According to the distribution of the Adipo-IRI, $\mathrm{P}_{66.7}$ was 2.94 in males and 3.87 in females, which were defined as the cut-off points for adipose tissue insulin resistance. Based on these cutoffs, 77 males and 89 females were defined as exhibiting adipose tissue insulin resistance. The values of all anthropometric indicators were distributed differently between the subjects with and without adipose tissue insulin resistance, and individuals with adipose tissue insulin resistance were more likely to be more obese and to have a history of diabetes, hypertension, CVD and fatty liver (table 1).

\section{Obesity defined by various anthropometric indicators associated with adipose tissue insulin resistance}

After adjusting for potential confounding factors of age, income, education level, current smoking and drinking status, SBP, DBP, FPG, 2 h-PG, HDL-C, LDL-C, TG and TC, we found BMI (male: $\beta=0.61$, female: $\beta=0.72$ ), NC (male: $\beta=0.48$, female: $\beta=0.64$ ), WC (male: $\beta=0.67$, female: $\beta=0.68$ ) and WHR (male: $\beta=0.41$, female: $\beta=0.33$ ) to be significantly correlated in both males and females with Adipo-IRI, as shown in online supplementary figure S1. Further, all anthropometric indicators were also independently and positively associated with the presence of adipose tissue insulin resistance. For males, the strength (OR $(95 \% \mathrm{CI})$ ) of association with adipose tissue insulin resistance were the following: BMI: 2.65 (1.65 to 4.27 ), NC: 2.96 (1.37 to 3.21 ), WC: 3.43 (2.03 to 5.82 ) and WHR: 1.59 (1.03 to 2.44 ). For females, the corresponding strength of association with adipose tissue insulin resistance were BMI: 3.08 (2.04 to 4.66$)$, NC: 2.65 (1.77 to 3.98), WC: 2.91 (1.97 to 4.30) and WHR: 1.78 (1.26 to 2.52) (table 2). Among these anthropometric indicators, WC $(\mathrm{OR}=3.43(2.03$ 
Table 1 Characteristic of participants categorized by gender and insulin resistance status of adipose tissue

\begin{tabular}{|c|c|c|c|c|c|c|}
\hline & \multirow[b]{2}{*}{$\begin{array}{l}\text { Adipose-IR } \\
(\mathrm{n}=77)\end{array}$} & \multirow{2}{*}{$\begin{array}{l}\text { Male } \\
\begin{array}{l}\text { Non-adipose-IR } \\
(n=155)\end{array}\end{array}$} & \multirow[b]{2}{*}{$P$ value } & \multirow[b]{2}{*}{$\begin{array}{l}\text { Adipose-IR } \\
(\mathrm{n}=89)\end{array}$} & \multirow{2}{*}{$\begin{array}{l}\text { Female } \\
\begin{array}{l}\text { Non-adipose-IR } \\
(\mathrm{n}=178)\end{array}\end{array}$} & \multirow[b]{2}{*}{$P$ value } \\
\hline & & & & & & \\
\hline Age, years & $58.9 \pm 6.9$ & $60.9 \pm 6.8$ & 0.03 & $61.2 \pm 7.3$ & $59.7 \pm 6.7$ & 0.41 \\
\hline Average income/month, yuan & $1600(1175-3000)$ & 2000 (1250-2500) & 0.93 & $1600(1000-2500)$ & $1600(1187-2500)$ & 0.61 \\
\hline Education, n (\%) & & & 0.05 & & & - \\
\hline Low & $31(40.3)$ & $84(54.2)$ & & $62(69.7)$ & $124(69.7)$ & \\
\hline Intermediate & $35(45.5)$ & $45(29.0)$ & & $24(27.0)$ & $41(23.0)$ & \\
\hline High & $11(14.3)$ & $26(16.8)$ & & $3(3.4)$ & $13(7.3)$ & \\
\hline Current smoking status, $\mathrm{n}(\%)$ & & & 0.14 & & & - \\
\hline No smoking & $16(20.8)$ & $25(16.1)$ & & $89(100.0)$ & $178(100.0)$ & \\
\hline Smoking & $33(42.9)$ & $88(56.8)$ & & 0 & 0 & \\
\hline Quit smoking & $28(36.4)$ & $42(27.1)$ & & 0 & 0 & \\
\hline Current drinking status, $\mathrm{n}(\%)$ & & & 0.35 & & & 0.19 \\
\hline No drinking & $17(22.1)$ & $42(27.1)$ & & $60(67.4)$ & $107(60.1)$ & \\
\hline Drinking & $56(72.7)$ & 99 (63.9) & & $29(32.6)$ & $66(37.1)$ & \\
\hline Quite drinking & $4(5.2)$ & $14(9.0)$ & & 0 & $5(2.8)$ & \\
\hline Body mass index, $\mathrm{kg} / \mathrm{m}^{2}$ & $24.3 \pm 2.8$ & $21.6 \pm 2.5$ & $<0.001$ & $24.9 \pm 2.9$ & $22.2 \pm 2.5$ & $<0.001$ \\
\hline Neck circumference, cm & $37.9 \pm 2.6$ & $35.8 \pm 2.3$ & $<0.001$ & $34.8 \pm 2.3$ & $32.8 \pm 2.1$ & $<0.001$ \\
\hline Waist circumference, $\mathrm{cm}$ & $90.9 \pm 7.4$ & $82.7 \pm 7.8$ & $<0.001$ & $89.8 \pm 8.0$ & $81.3 \pm 8.0$ & $<0.001$ \\
\hline Waist-hip ratio & $0.9 \pm 0.1$ & $0.9 \pm 0.1$ & $<0.001$ & $0.9 \pm 0.1$ & $0.9 \pm 0.1$ & $<0.001$ \\
\hline $\begin{array}{l}\text { Fasting plasma glucose, } \\
\mathrm{mmol} / \mathrm{L}\end{array}$ & $5.6(5.3-6.0)$ & $5.3(5.0-5.6)$ & $<0.001$ & $5.7(5.4-6,4)$ & $5.3(5.0-5.7)$ & $<0.001$ \\
\hline $\begin{array}{l}2 \text { hour plasma glucose, } \\
\mathrm{mmol} / \mathrm{L}\end{array}$ & $8.1(7.0-9.7)$ & $7.1(5.9-8.8)$ & 0.001 & $8.1(7.0-10.5)$ & $6.7(5.8-8.0)$ & $<0.001$ \\
\hline $\begin{array}{l}\text { Systolic blood pressure, } \\
\mathrm{mm} \mathrm{Hg}\end{array}$ & $126.2 \pm 14.3$ & $120.8 \pm 13.4$ & 0.010 & $133.2 \pm 14.2$ & $122.2 \pm 16.8$ & $<0.001$ \\
\hline $\begin{array}{l}\text { Diastolic blood pressure, } \\
\text { mm Hg }\end{array}$ & $76.0 \pm 8.7$ & $72.9 \pm 8.4$ & 0.012 & $75.9 \pm 8.8$ & $70.2 \pm 8.4$ & $<0.001$ \\
\hline Total cholesterol, $\mathrm{mmol} / \mathrm{L}$ & $5.0(4.3-5.7)$ & $4.7(4.1-5.2)$ & 0.003 & $5.3(4.6-5.8)$ & $5(4.3-5.4)$ & 0.018 \\
\hline Triglycerides, mmol/L & $1.9(1.3-2.7)$ & $1.2(0.8-1.6)$ & $<0.001$ & $1.7(1.3-2.4)$ & $1.2(0.9-1.6)$ & $<0.001$ \\
\hline $\mathrm{HDL}-\mathrm{C}, \mathrm{mmol} / \mathrm{L}$ & $1.1(0.9-1.4)$ & $1.3(1.1-1.6)$ & $<0.001$ & $1.3(1.1-1.4)$ & $1.4(1.2-1.6)$ & 0.005 \\
\hline LDL-C, mmol/L & $2.7(2.2-3.1)$ & $2.5(2.1-2.8)$ & 0.020 & $2.7(2.3-3.2)$ & $2.6(2.2-3.0)$ & 0.25 \\
\hline Adipose-IRI & $3.7(3.1-4.8)$ & $1.4(1.1-1.9)$ & $<0.001$ & $5.2(4.1-6.7)$ & $2.3(1.7-2.8)$ & $<0.001$ \\
\hline Dyslipidemia, n (\%) & $61(79.2)$ & $69(44.5)$ & $<0.001$ & $70(78.7)$ & $100(56.2)$ & $<0.001$ \\
\hline Diabetes, n (\%) & $14(18.2)$ & 20 (12.9) & 0.28 & 27 (30.3) & $24(13.5)$ & 0.001 \\
\hline Hypertension, n (\%) & $32(41.6)$ & $36(23.2)$ & 0.004 & $54(60.7)$ & $55(30.9)$ & $<0.001$ \\
\hline CVD, n (\%) & $7(9.1)$ & $8(5.2)$ & 0.25 & $12(13.5)$ & $13(7.3)$ & 0.10 \\
\hline Fatty liver, n (\%) & $13(16.9)$ & $8(5.2)$ & 0.003 & $19(21.3)$ & $11(6.2)$ & $<0.001$ \\
\hline
\end{tabular}

Data expression: means \pm SD for normal continuous variables, median (IQR) for non-normal continuous variables or numbers and percentages for categorical variables. Statistics analysis: two-sample t-test for normal continuous variables, Mann-Whitney $U$ test for non-normal continuous variables and $\chi^{2}$ test for categorical variables.

Adipose-IRI, adipose tissue insulin resistance index; Average income, average monthly income per person in family; CVD, cerebralcardiovascular diseases; HDL-C, high-density lipoprotein cholesterol; LDL-C, low-density lipoprotein cholesterol.

to 5.82)) in males and BMI ( $\mathrm{OR}=3.08$ (2.04 to 4.66)) in females were the strongest indicators associated with adipose tissue insulin resistance. In males, the strength of association of adipose tissue insulin resistance with TG $(\mathrm{OR}=3.21$ (1.28 to 8.04$))$ was similar to that with
WC. Other plasma lipids in males were not associated with adipose tissue insulin resistance, including TC, HDL-C and LDL-C. The lipid profiles were not associated with adipose tissue insulin resistance in females (online supplementary table S1). 
Table 2 Association of anthropometric indicators with adipose tissue insulin resistance stratified by gender

\begin{tabular}{|c|c|c|c|c|c|c|}
\hline & \multicolumn{2}{|l|}{ Model I } & \multicolumn{2}{|l|}{ Model II } & \multicolumn{2}{|l|}{ Model III } \\
\hline & OR $(95 \% \mathrm{Cl})$ & P value & OR $(95 \% \mathrm{Cl})$ & $P$ value & OR $(95 \% \mathrm{Cl})$ & P value \\
\hline \multicolumn{7}{|l|}{ Male } \\
\hline BMI & 3.12 (2.17 to 4.49$)$ & $<0.001$ & 3.30 (2.19 to 4.96$)$ & $<0.001$ & 2.65 (1.65 to 4.27$)$ & $<0.001$ \\
\hline Neck circumference & 2.83 (2.00 to 3.99$)$ & $<0.001$ & 2.78 (1.91 to 4.04$)$ & $<0.001$ & 2.96 (1.37 to 3.21$)$ & $<0.001$ \\
\hline Waist circumference & 3.49 (2.36 to 5.16$)$ & $<0.001$ & 3.62 (2.38 to 5.50$)$ & $<0.001$ & 3.43 (2.03 to 5.82 ) & $<0.001$ \\
\hline WHR & 2.12 (1.53 to 2.92$)$ & $<0.001$ & 2.09 (1.49 to 2.94$)$ & $<0.001$ & 1.59 (1.03 to 2.44$)$ & 0.036 \\
\hline \multicolumn{7}{|l|}{ Female } \\
\hline BMI & 3.04 (2.19 to 4.22$)$ & $<0.001$ & 3.23 (2.29 to 4.56$)$ & $<0.001$ & 3.08 (2.04 to 4.66$)$ & $<0.001$ \\
\hline Neck circumference & 2.96 (2.13 to 4.13$)$ & $<0.001$ & 3.02 (2.14 to 4.25$)$ & $<0.001$ & 2.65 (1.77 to 3.98$)$ & $<0.001$ \\
\hline Waist circumference & 2.92 (2.11 to 4.03$)$ & $<0.001$ & 3.03 (2.17 to 4.24$)$ & $<0.001$ & 2.91 (1.97 to 4.30$)$ & $<0.001$ \\
\hline WHR & 1.91 (1.44 to 2.53$)$ & $<0.001$ & 1.98 (1.48 to 2.66$)$ & $<0.001$ & 1.78 (1.26 to 2.52$)$ & 0.001 \\
\hline
\end{tabular}

Data were from logistic regression analysis. OR: odds ratio (per SD increase in each anthropometric indicators).

Model I, unadjusted; Model II, adjusted for age, income, education level, current smoking status and current drinking status; Model III,

Model II+adjusted for SBP, DBP, FPG, 2 h-PG, HDL-C, LDL-C, TG and TC.

$\mathrm{BMI}$, body mass index; DBP, diastolic blood pressure; FPG, fasting plasma glucose; HDL-C, high density lipoprotein cholesterol; 2h-PG, 2hour plasma glucose; LDL-C, low density lipoprotein cholesterol; SBP, systolic blood pressure; TC, total cholesterol; TG, triglyceride; WHR, waist/hip ratio.

To confirm the association, subgroup analysis was performed. WC and BMI were still the strongest anthropometric indicators associated with adipose tissue insulin resistance in males and females after excluding subjects with diabetes, GVD or fatty liver individually or with all these diseases combined (online supplementary table S2).

\section{Diagnostic value of anthropometric indicators for adipose tissue insulin resistance}

To compare the diagnostic value of anthropometric indicators in identifying the presence of adipose tissue insulin resistance, we performed a ROC analysis. The power of anthropometric indicators in identifying adipose tissue insulin resistance was very close in both genders, with the area under the curve (AUC) for males being WC: 0.79 , BMI: 0.77 , NC: 0.75 and WHR: 0.69 ; and for females being WC: 0.78 , BMI: 0.77, NC: 0.77 and WHR: 0.67 (figure 1). Therefore, for males, WC was the best indicator in identifying adipose tissue insulin resistance, whereas for females, BMI was the best indicator. The diagnostic power for adipose tissue insulin resistance of WC and BMI were higher than the lipid profile including TC (AUC: 0.62 for male, 0.59 for female), TG (AUC: 0.74 for male, 0.72 for female), HDL-C (AUC: 0.59 for male, 0.54 for female) and LDL-C (AUC:0.35 for male, 0.40 for female) regardless of the gender (online supplementary
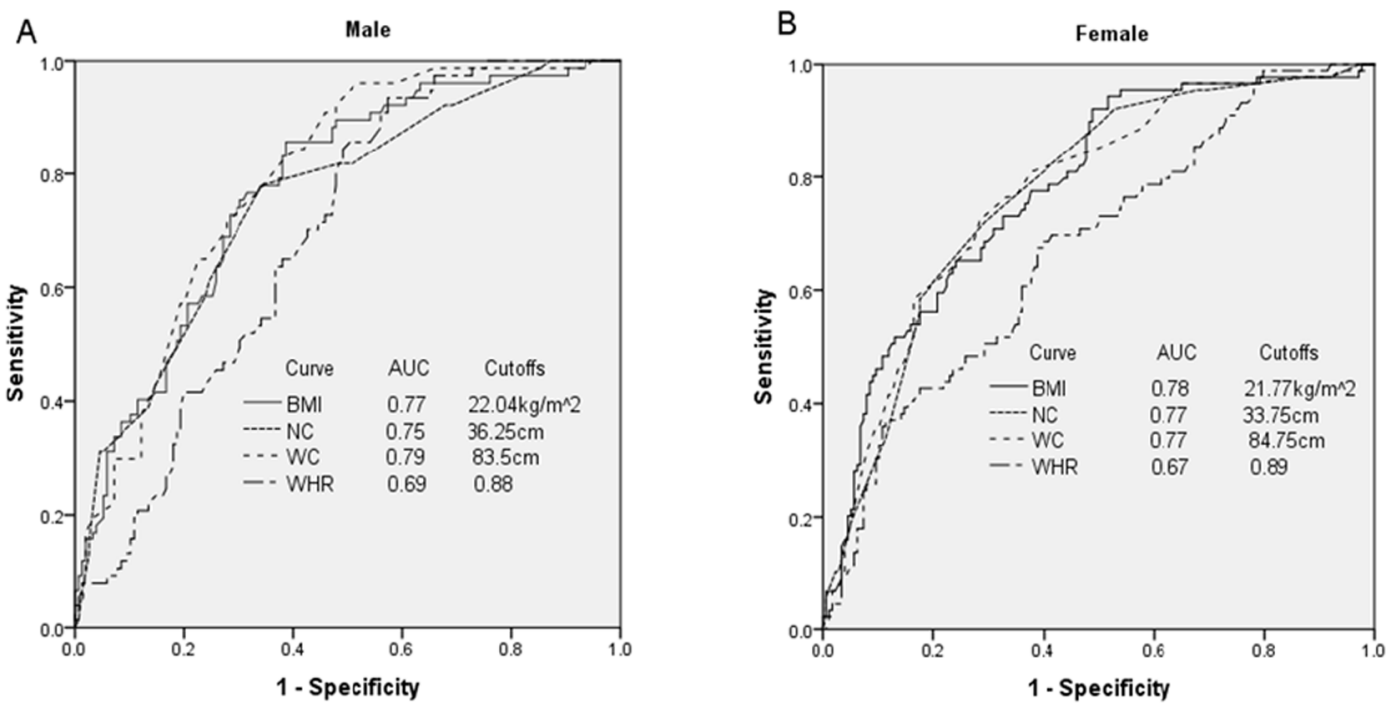

Figure 1 ROC curves of each anthropometric indicator for distinguishing Adipo-IR in male (A) and female (B) subjects in the study population. AUC, area under the curve; BMI, body mass index; NC, neck circumference; ROC, receiver operating characteristic; WC, waist circumference; WHR, waist/hip ratio. 
Table 3 The attribution risk of obesity for the prevalence of adipose tissue insulin resistance

\begin{tabular}{|c|c|c|c|c|c|}
\hline & It (\%) & Io $\left(\mathrm{n}_{0} / \mathrm{N}_{0}\right)$ & le $\left(\mathrm{n}_{\mathrm{e}} / \mathrm{N}_{\mathrm{e}}\right)$ & $\begin{array}{l}\text { ARP } \\
(\%)\end{array}$ & $\begin{array}{l}\text { PARP } \\
(\%)\end{array}$ \\
\hline \multicolumn{6}{|l|}{ Total } \\
\hline Abdominal obesity (WC $\geq 90 \mathrm{~cm}$ for male and $W C \geq 80 \mathrm{~cm}$ for female) & 33.3 & $43 / 243$ & $123 / 256$ & 63.1 & 46.8 \\
\hline \multicolumn{6}{|l|}{ Male } \\
\hline Cut-off point in this study $(\mathrm{WC} \geq 83.5 \mathrm{~cm})$ & 33.3 & $7 / 91$ & $70 / 141$ & 84.5 & 76.9 \\
\hline \multicolumn{6}{|l|}{ Female } \\
\hline General obesity $\left(\mathrm{BMI} \geq 25 \mathrm{~kg} / \mathrm{m}^{2}\right)$ & 33.3 & $46 / 203$ & $43 / 64$ & 66.2 & 31.8 \\
\hline Abdominal obesity (WC $\geq 80 \mathrm{~cm})$ & 33.3 & $10 / 85$ & $79 / 182$ & 72.8 & 64.5 \\
\hline
\end{tabular}

ARP, attributable risk per cent; BMI, body mass index; le, prevalence of adipose tissue insulin resistance for the obese group included in obesity defined by $\mathrm{BMl} \geq 25 \mathrm{~kg} / \mathrm{m}^{2}$ (whole body obesity), WC $\geq 80 \mathrm{~cm}$ for female/90 $\mathrm{cm}$ for male (abdominal obesity) or cut-off value in this study ( $\mathrm{WC} \geq 83.5 \mathrm{~cm}$ for male and $\mathrm{BMl} \geq 21.77 \mathrm{~kg} / \mathrm{m}^{2}$ for female); lo, prevalence of adipose tissue insulin resistance for non-obese population; It, prevalence of adipose tissue insulin resistance for the study population; PARP, population attributable risk per cent; WC, waist circumference.

table S1). According to the maximum value of the Youden index, the best cut-off points for determining adipose tissue insulin resistance in males were $\mathrm{WC} \geq 83.5 \mathrm{~cm}$ for males with a sensitivity of $90.9 \%$ and specificity of $54.2 \%$; and in females, it was BMI $\geq 21.77 \mathrm{~kg} / \mathrm{m}^{2}$ with a sensitivity of $92.1 \%$ and specificity of $51.1 \%$ (online supplementary table S3).

\section{Contribution of obesity to adipose tissue insulin resistance in the study population}

To assess the contribution of obesity to adipose tissue insulin resistance in the obese subjects, ARP was calculated (table 3). General obesity in obese males and females attributed to $61.3 \%$ and $66.2 \%$ of the adipose tissue resistance, respectively, whereas abdominal obesity attributed to $64.9 \%$ and $72.8 \%$ of the adipose tissue insulin resistance, respectively, in abdominal obese males and females. Obesity, defined by cut-off values derived from the ROC analysis in males (WC $\geq 83.5 \mathrm{~cm}$ ) and females (BMI $\geq 21.77 \mathrm{~kg} / \mathrm{m}^{2}$ ), attributed to $84.5 \%$ and $85.4 \%$ of the adipose tissue insulin resistance.

We also assessed the contribution of obesity to adipose tissue insulin resistance in the study population, that is, PARP. Here, general obesity attributed to $27.3 \%$ of the adipose tissue resistance in the entire study population, $22.5 \%$ in males and $31.8 \%$ in females. Abdominal obesity attributed to $46.8 \%$ of adipose tissue insulin resistance in the entire study population, $37.2 \%$ in males and $64.5 \%$ in females. When obesity was defined by the ROC analysis cut-off points, abdominal obesity (WC $\geq 83.5 \mathrm{~cm}$ ) attributed to $76.9 \%$ of the adipose tissue insulin resistance in males, and general obesity (BMI $\geq 21.77 \mathrm{~kg} / \mathrm{m}^{2}$ ) attributed to $78.7 \%$ of adipose tissue insulin resistance in females.

\section{Clinical implication of adipose tissue insulin resistance}

To better understand the potential influence of adipose tissue insulin resistance on metabolic disease, we stratified the participants into four different obesity phenotypes as B0W0 (no general obesity+no abdominal obesity), B0W1 (no general obesity+abdominal obesity), B1W0 (general obesity+no abdominal obesity) and B1W1 (general obesity+abdominal obesity). As shown in online supplementary table S4, phenotype B1W1 had the highest prevalence of adipose tissue insulin resistance of $70.7 \%$ (70/99). Notably, $17.8 \%(42 / 236)$ of participants with the phenotype B0W0 also had adipose tissue insulin resistance. We further demonstrated that participants with adipose tissue insulin resistance had a relatively higher prevalence of type 2 diabetes, CVD and fatty liver than their same obesity phenotype partner without adipose tissue insulin resistance (figure 2). Although most of the comparisons were not statistically significant, the ORs of the metabolic disease in the phenotype B0W0 were significant or trended to be significant (online supplementary table S5), which indicated that adipose tissue insulin resistance was associated or trended to be associated with the metabolic diseases in subjects with this obesity phenotype.

\section{DISCUSSION}

In this study, we have demonstrated that the different anatomical forms of obesity defined by various anthropometric indicators including BMI, NC, WC and WHR were all positively and independently associated with the presence of adipose tissue insulin resistance in both males and females. In males, WC was the strongest indicator associated with adipose tissue insulin resistance 
Diabetes

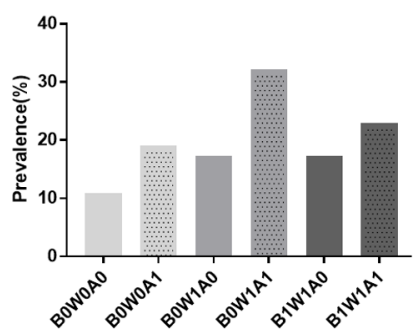

CVD

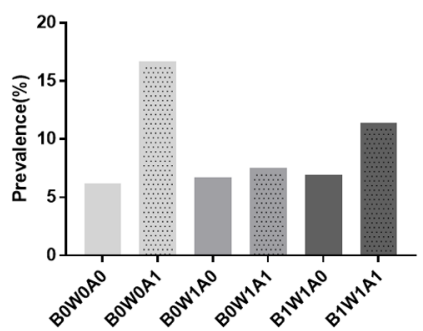

Fat liver

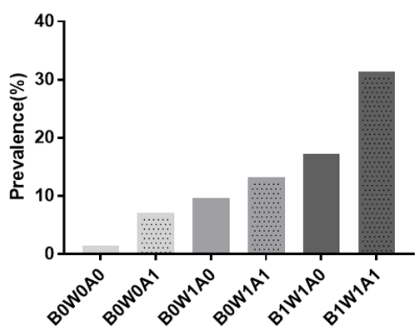

Figure 2 Prevalence of metabolic diseases in the different groups. A0/A1, without/with adipose tissue insulin resistance; B0/ B1, without/with general obesity; CVD, cardiovascular disease; W0/W1, without/with abdominal obesity.

and was also the best marker for adipose tissue insulin resistance. Additionally, abdominal obesity (WC $\geq 90 \mathrm{~cm}$ ) accounted for $64.9 \%$ of the adipose tissue insulin resistance in the obese male subjects. In females, BMI was the strongest indicator associated with and the major marker of adipose tissue insulin resistance. General obesity $\left(\mathrm{BMI} \geq 25 \mathrm{~kg} / \mathrm{m}^{2}\right.$ ) accounted for $66.2 \%$ of adipose tissue insulin resistance in the obese female subjects. To the best of our knowledge, this is the first study to investigate the relationship between different phenotypes of obesity and adipose tissue insulin resistance.

Sex differences were found in adipose tissue insulin resistance. First, the levels of Adipo-IRI in females(2.84) were higher than those in males(1.87). This finding was similar to the result from the Manfred James Müller's study on peripheral insulin resistance. ${ }^{22}$ In this study, most of the participants were most likely postmenopausal women (aged 50 years and over). They exhibit lower serum estrogen levels than premenopausal women, ${ }^{23}$ and estrogen deficiency was associated with increased inflammation $^{24}$ and development of obesity-induced insulin resistance, which may be a reason for females in this study to exhibit higher adipo-IRI. ${ }^{142526}$ Sex hormones also contribute to the different body fat distribution, ${ }^{23} 24$ where males tended to have more central fat distribution whereas females tended to have more peripheral and subcutaneous fat distribution. ${ }^{22} 27$ This at least in part explains why our study found WC, which reflects abdominal obesity, to be the strongest indicator associated with and is the major marker of adipose tissue insulin resistance in males, whereas BMI, which reflects general obesity, was found to be the strongest factor and major marker of adipose tissue insulin resistance in females.

This study provides direct evidence that delineated the relationship between obesity, adipose tissue insulin resistance and metabolic diseases. Although we demonstrated that abdominal obesity and general obesity were the most closely associated with adipose tissue insulin resistance in males and females, respectively, our attribution analysis nevertheless showed that general and abdominal obesity accounted for only $27.3 \%$ and $46.8 \%$ of the adipose tissue insulin resistance in the study population, respectively. These results indicated that reasons other than obesity may also account for adipose tissue insulin resistance. We found that $18 \%$ of participants with normal BMI and WC exhibited adipose tissue insulin resistance. This taken together with the results of adipose tissue insulin resistance being associated with the prevalence of CVD and a trend towards association with the prevalence of type 2 diabetes and fatty liver in subjects with phenotype B0W0, led us to conclude that adipose tissue insulin resistance may also exist and contribute to diseases in lean subjects. The etiology of adipose tissue insulin resistance in lean subjects, especially in elderly lean subjects who were also participants of this study, deserves further investigation. Although the prevalence of these metabolic diseases in phenotypes B1W1 and B0W1 with adipose tissue insulin resistance was also higher than their counterparts with same obesity phenotypes, a statistical significance was not reached. This may be partly due to the relatively small sample size and small number of participants with metabolic diseases in this study. This hypothesis could be supported by more significant differences in the obesity phenotype B0W0 where we had larger sample sizes (B0W0: $\mathrm{n}=236$; B0W0: $\mathrm{n}=157$; B1W0: $\mathrm{n}=7$; B1W1: $\mathrm{n}=99$ ). These results taken together indicate that adipose insulin resistance may serve as a therapeutic target for controlling the occurrence of metabolic diseases, even in lean subjects.

Since adipose tissue insulin resistance might be the important origin of systemic (peripheral) insulin resistance and a risk factor for some metabolic diseases, ${ }^{3-7}$ there is an urgent need in elucidating the more apparent clinical markers. WC for males (AUC: 0.79) and BMI for females (AUC: 0.78) are the highest value anthropometric indicators for the diagnosis of adipose tissue insulin resistance. In fact, these indicators have even higher diagnostic values than TG ( $\mathrm{AUC}$ : 0.74 for male, 0.72 for female), which has been conventionally associated with insulin resistance, and taken together with their non-invasive, low cost and convenience in taking these physical measurements, lead us to propose that these anthropometric indicators could be superior clinical alternatives to diagnose adipose tissue insulin resistance.

The major strength of this study was the association between obesity and adipose insulin resistance, which was confirmed by subgroups analysis in which subjects with diabetes, CVD or fatty liver were individually excluded, or all three conditions combined that were excluded. However, this study still has limitations inherent to its cross-sectional design, and the community 
population limited to those aged 50 years and over may weaken its representativeness or application to the whole population.

In conclusion, since we demonstrated that obesity, defined by WC and BMI, contribute to about two-thirds of the observed adipose tissue insulin resistance in males and females, respectively; and together with the finding that WC and BMI were the strongest indicators associated with or were the best predictive markers for adipose tissue insulin resistance, we reason that maintaining the $\mathrm{WC}$ in males and $\mathrm{BMI}$ in females to their respective favorable ranges would be an important strategy to reduce the occurrence of adipose tissue insulin resistance with the ensuing improvement in metabolic disorder and diseases. People with adipose tissue insulin resistance showed a relatively higher risk of metabolic disease than their same obesity phenotype counterpart without adipose tissue insulin resistance. Thus, our efforts should be exerted at exploring for interventions that are directed at adipose tissue insulin resistance per se rather than at obesity.

\section{Author affiliations}

'Department of Epidemiology and Biostatistics, School of Public Health, Capital Medical University, Beijing, China

${ }^{2}$ Department of Endocrinology, Jining No. 1 People's Hospital, Jining, Shandong, China

${ }^{3}$ Department of Neurology, Lishui Central Hospital and Fifth Affiliated Hospital of Wenzhou Medical College, Lishui, Zhejiang, China

${ }^{4}$ Department of Neurology, Beijing Tiantan Hospital, Beijing, China

${ }^{5}$ Department of Statistics, China National Clinical Research Center for Neurological Diseases, Beijing, China

${ }^{6}$ Department of Laboratory Animal, School of Basic Medical Sciences, Capital Medical University, Beijing, China

${ }^{7}$ Departments of Medicine and Physiology, University of Toronto, Toronto, Ontario, Canada

${ }^{8}$ Municipal Key Laboratory of Clinical Epidemiology, Beijing, China

Acknowledgements The authors appreciate the efforts of all participants who contributed to the sample measurements and data collection.

Contributors Each author has been involved in and contributed to this manuscript. Conceptualization: DZ and TW. Data curation: JJ and YP. Formal analysis: $\mathrm{JJ}$ and $\mathrm{XC}$. Investigation: YP and XY. Methodology: HZ and XY. Project administration: TW and YH. Software: DZ. Supervision: XD and HZ. Validation: XD. Visualization: $X C$. Writing —original draft: JJ and XC. Writing —review and editing: $\mathrm{HG}$ and $\mathrm{YH}$. All authors approved final version of the manuscript to be published.

Funding This study was supported by National Natural Science Foundation of China (31672375) to YH, Ministry of Science and Technology of the People's Republic of China (2017YFC1310902,2018YFC1311700 and 2018YFC1311706), National Natural Science Foundation of China (81971091) and Beijing Hospitals Authority Youth Programme (QML20190501) to YP, Lishui Science \&Technology Bureau(2019ZDYF18)

Competing interests None declared.

Patient consent for publication Not required.

Ethics approval All subjects gave written informed consent in accordance with the Declaration of Helsinki. The protocol was approved by the Committee on Human Research of the Lishui Central Hospital.

Provenance and peer review Not commissioned; externally peer reviewed.

Data availability statement No data are available. Because follow-up study of this investigation is still in progress, data sharing cannot be carried out for now.

Open access This is an open access article distributed in accordance with the Creative Commons Attribution Non Commercial (CC BY-NC 4.0) license, which permits others to distribute, remix, adapt, build upon this work non-commercially, and license their derivative works on different terms, provided the original work is properly cited, appropriate credit is given, any changes made indicated, and the use is non-commercial. See: http://creativecommons.org/licenses/by-nc/4.0/.

ORCID iDs

Yuesong Pan http://orcid.org/0000-0003-3082-6789

Yan He http://orcid.org/0000-0002-8586-075X

\section{REFERENCES}

1 Luo L, Liu M. Adipose tissue in control of metabolism. J Endocrinol 2016;231:R77-99.

2 Delarue J, Magnan C. Free fatty acids and insulin resistance. Curr Opin Clin Nutr Metab Care 2007;10:142-8.

3 Kelsey MM, Forster JE, Van Pelt RE, et al. Adipose tissue insulin resistance in adolescents with and without type 2 diabetes. Pediatr Obes 2014;9:373-80.

4 Gastaldelli A, Gaggini M, DeFronzo RA. Role of adipose tissue insulin resistance in the natural history of type 2 diabetes: results from the San Antonio metabolism study. Diabetes 2017;66:815-22.

5 Armstrong MJ, Hazlehurst JM, Hull D, et al. Abdominal subcutaneous adipose tissue insulin resistance and lipolysis in patients with non-alcoholic steatohepatitis. Diabetes Obes Metab 2014;16:651-60.

6 Gastaldelli A, Harrison SA, Belfort-Aguilar R, et al. Importance of changes in adipose tissue insulin resistance to histological response during thiazolidinedione treatment of patients with nonalcoholic steatohepatitis. Hepatology 2009;50:1087-93.

7 Jorge-Galarza E, Posadas-Romero C, Torres-Tamayo M, et al. Insulin resistance in adipose tissue but not in liver is associated with aortic valve calcification. Dis Markers 2016;2016:9085474

8 Magkos F, Mittendorfer B. Stable isotope-labeled tracers for the investigation of fatty acid and triglyceride metabolism in humans in vivo. Clin Lipidol 2009;4:215-30.

9 Søndergaard E, Espinosa De Ycaza AE, Morgan-Bathke M, et al. How to measure adipose tissue insulin sensitivity. J Clin Endocrinol Metab 2017;102:1193-9.

10 Ter Horst KW, van Galen KA, Gilijamse PW, et al. Methods for quantifying adipose tissue insulin resistance in overweight/obese humans. Int J Obes 2017;41:1288-94.

$11 \mathrm{Kim}$ JI, Huh JY, Sohn JH, et al. Lipid-overloaded enlarged adipocytes provoke insulin resistance independent of inflammation. Mol Cell Biol 2015;35:1686-99.

12 Greenberg AS, Obin MS. Obesity and the role of adipose tissue in inflammation and metabolism. Am J Clin Nutr 2006;83:461S-5.

13 Lafontan M. Adipose tissue and adipocyte dysregulation. Diabetes Metab 2014;40:16-28.

14 Lee B-C, Lee J. Cellular and molecular players in adipose tissue inflammation in the development of obesity-induced insulin resistance. Biochim Biophys Acta 2014;1842:446-62.

$15 \mathrm{Kim}$ JY, Bacha F, Tfayli $\mathrm{H}$, et al. Adipose tissue insulin resistance in youth on the spectrum from normal weight to obese and from normal glucose tolerance to impaired glucose tolerance to type 2 diabetes. Diabetes Care 2019;42:265-72.

16 Hagman E, Besor O, Hershkop K, et al. Relation of the degree of obesity in childhood to adipose tissue insulin resistance. Acta Diabetol 2019;56:219-26.

17 Jiang J, Cui J, Yang X, et al. Neck circumference, a novel indicator for hyperuricemia. Front Physiol 2017;8:965.

18 Mbanya VN, Kengne AP, Mbanya JC, et al. Body mass index, waist circumference, hip circumference, waist-hip-ratio and waist-heightratio: which is the better discriminator of prevalent screen-detected diabetes in a Cameroonian population? Diabetes Res Clin Pract 2015;108:23-30.

$19 \mathrm{Li} \mathrm{S}$, Xiao J, Ji L, et al. Bmi and waist circumference are associated with impaired glucose metabolism and type 2 diabetes in normal weight Chinese adults. J Diabetes Complications 2014;28:470-6.

20 Friedewald WT, Levy RI, Fredrickson DS. Estimation of the concentration of low-density lipoprotein cholesterol in plasma, without use of the preparative ultracentrifuge. Clin Chem 1972;18:499-502.

21 Leon-Acuña A, Alcala-Diaz JF, Delgado-Lista J, et al. Hepatic insulin resistance both in prediabetic and diabetic patients determines postprandial lipoprotein metabolism: from the CORDIOPREV study. Cardiovasc Diabetol 2016;15:68.

22 Hübers M, Pourhassan M, Braun W, et al. Definition of new cut-offs of BMI and waist circumference based on body composition and insulin resistance: differences between children, adolescents and adults. Obes Sci Pract 2017;3:272-81. 
23 Garaulet M, Pérex-Llamas F, Fuente T, et al. Anthropometric, computed tomography and fat cell data in an obese population: relationship with insulin, leptin, tumor necrosis factor-alpha, sex hormone-binding globulin and sex hormones. Eur J Endocrinol 2000;143:657-66.

24 Varghese M, Griffin C, Singer K. The role of sex and sex hormones in regulating obesity-induced inflammation. Adv Exp Med Biol 2017;1043:65-86.
25 Ahnstedt H, Roy-O'Reilly M, Spychala MS, et al. Sex Differences in Adipose Tissue CD8 ${ }^{+} \mathrm{T}$ Cells and Regulatory T Cells in Middle-Aged Mice. Front Immunol 2018;9:659.

26 Adams-Huet B, Devaraj S, Siegel D, et al. Increased adipose tissue insulin resistance in metabolic syndrome: relationship to circulating adipokines. Metab Syndr Relat Disord 2014;12:503-7.

27 Geer EB, Shen W. Gender differences in insulin resistance, body composition, and energy balance. Gend Med 2009;6 Suppl 1:60-75. 